Philosophy

\title{
Management of Stress: From the Perspectives of the Natural Theory Philosophers
}

\section{Ncha Gabriel Bubu ${ }^{1}$}

\author{
${ }^{1}$ Department of Philosophy. University of Calabar. Calabar, Cross River State, \\ Nigeria.
}

Article History

Received:

13.07.2020

Revised:

29.08.2020

Accepted:

30.08 .2020

*Corresponding Author:

Ncha Gabriel Bubu

Email:

nchagabriel@ymail.com

This is an open access article, licensed under: $\mathrm{CC}-\mathrm{BY}-\mathrm{SA}$

\section{(c) (i) (2)}

Abstract: The phenomenon of stress among humans, has become a disturbing one and a source of worry and sorrow for millions of people all over the world. This, in most cases, has resulted in deaths, strokes and paralysis, and if these occur with individuals that are bread winners in families, the consequences could be devastating as members of such families who are dependent on the bread winners would be put into untold hardship which could result in further stress related problems. One important cause of this phenomenon is poor management of stress and the lack of a suitable stress management strategy. This paper examines this phenomenon and argues that the natural theorist approach could be therapeutic. The method adopted is expository and content analysis.

Keywords: Natural Theory, Philosophy, Stress. 


\section{Introduction}

In every day, in the life of humans, one could observe that people move from place to place in search of different things and for numerous reasons. Such movements are usually or mostly envelops in economic activities which are activities that take a greater part of most human beings [1]. These attempts to make ends meet or to satisfy our taste or desires, in life could be vitiated by the hardship, pains and displeasure that naturally come as a consequence. Following this, stress could set in and thus the individual involved may loose balance and could be driven into a discomforting mood, and this may begin to affect one's relationship with others within the same environment. When this happens, one's utility maximization becomes the victim, and this may lead to lower output and loss of income or revenue.

Given the above, it is logical and necessarily important that stress related problems should be studied with a view to proffering solutions in order to curb or checkmate the menace of stress. Here, we briefly periscope stress and its problems, and proffering a philosophical approach for solving or minimizing the problem from the angle of the natural theorists philosophers as an enduring solution.

\section{Stress Defined}

The oxford advanced learners dictionary, defines stress simply as a "pressure, tension, or worry resulting from problems in one's life" [2]. Stress may also be defined as the uneasiness and discomfort that is full of hassles, frustrations and demands. An outline essay on stress, gives the definition of stress as follows: "in psychological terms, stress is a feeling of pressure, strain, anxiety, being overwhelmed. It is characterized by overall irritability, feeling of insecurity, nervousness, withdrawal from social activities, loss of appetite, depression, frequent panic attacks, exhaustion, low/high blood pressure, skin problems, inability to sleep, migraine, gastrointestinal problems and menstrual problems in case of women and can lead to more serious problems such as heart attack etc [3].

Similarly, for Wikipedia, the free encyclopedia, "stress is a feeling of strain and pressure. Stress is a type of psychological pain. Small amounts of stress maybe desired, beneficial, and even healthy. Positive stress helps improve athletic performance. It also plays a factor in motivation, adaptation and reaction to the environment. Excessive amount of stress, however may lead to bodily harm. Stress can increase the risk of strokes, heart attacks, ulcers and mental illnesses such as depression" [4]. Giving credence to this, awake magazine write up on stress simply says "stress" "is the number one threat to our health and well-being".

In line with the above, s"stress is actually a normal part of life. At times, it serves a useful purpose, stress can motivate you to get the promotion at work, or on the last mile of a marathon" [5]. Indeed stress is common place and seems to have become a way of life. It is observed that stress is not always bad, if it is observed in small doses, it can help one to perform under pressure and motivate you to do one's best. Equally, when one works under emergency mode, then one's mind will definitely pay the price.

Experts explained that when one feels threatened, his or her nervous system becomes agitated and then releases a flow of stress hormones which include adrenaline or epinephrine, which sets the body for action. Okon, explains that this "hormone brings about rapid physiological responses to emergencies such as cold, heat, fight, fright, etc. hence this hormone is called emergency hormone or hormone of fight or fright. It elevates the blood glucose level by converting glycogen of liver into glucose. It raises the blood pressure by raising cardiac output [6].

It is worth mentioning that stress is responsible for many health problems such as:

- Heart disease

- Digestion problems

- Sleep problems

- Depression

- Obesity

- Auto - immune disease etc.

Again, awake write up paints an uglier picture of stress: "Because of the secretion of cortisol in long term stress, writes Van der Merwe, fats tends to accumulate around the abdomen and back. Skin disorders, such as eczema and psoriasis are associated with -or aggravated by stress. Severe stress has also been linked to depression, increased, aggression, and burnout. Memory and concentration too can 
be permanently impaired by constant stress. An immune system, seriously compromised by long term stress can make a person vulnerable to anything from the common cold to cancer and autoimmune diseases".

\section{Definition of Stressor}

According to Potter and Perry [7] "a stressor is any event, experience or environmental stimulus that causes stress in any individual. These events or experiences are perceived as threats or challenges to the individual and can be either physical or physiological". Stressor are situations that are experienced as a perceived threat to one's well-being or position in life, when the challenge of dealing with the problem which exceeds the persons perceived available resources. When one encounters stressors, the body's stress response is triggered and a series of physiological changes takes place to allow the person to fight or run. It could be said that when most people talk about stress, they are invariably talking about stress stressors. These are actually what lead to body's stress response, and the experience of stress according to stress experts.

Stressor could be likened to the following problems. That is under listed problems could be passed as stressor or causes of stress:

1. Accident situation

2. Academic failure

3. Death

4. Scam 419 played on one

5. Divorce

6. Imprisonment

7. Lost of love one

8. Illness HIV, other terminal diseases

9. Unemployment or dismissal from job

10. Retirement problems

11. Inability to get along with others

12. Conflict with spouse and other people

\section{Indicators and effects of stress}

There are numerous ways through which one can understand that stress is obvious. These are the signs and the effects or symptoms of stress and are discernable through the following:

\section{Cognitive symptoms}

1. Forgetfulness

2. Lack of understanding or focus

3. Irrelevant conclusion on issues

4. Appreciating only the negative

5. Anxiety or always agitated

Physical symptoms

1. Body pains

2. Unfree bowels/purging and releasing stools in a terrible frequency

3. Morning sickness and weakness and sometimes blurred vision

4. Increased heart pulse

5. Reduce libido and disinterestedness

6. Occasional neumonia

\section{Emotional symptoms}

1. Melancholy

2. Irascibility

3. Nervousness

4. Overwhelmed with negative thoughts

5. Withdrawal syndrome

6. Depression and anxiety 


\section{Behavioural symptoms}

1. Engaging in any act and loosing awareness of his surroundings

2. Indulging in vices, cultism, alcohol, drugs as a way of solving problems

3. Failing in one's responsibilities or becoming negligent or delay in duties performance

4. Loneliness

5. Suffering from insomnia or having an overdose of sleep

6. Glutonic sometimes and loss of appetite

There are so many symptoms that we may not be able to enumerate here. Basically our major concern is not the symptoms themselves but how to manage them is our business.

\section{Management and Control of Stress, the Natural Theorists' Perspective}

From time immemorial, the phenomenon of stress has been one of the disturbing issues of the human person. It straddles philosophers, psychologists and researchers from the ancient, medieval, modern and contemporary periods, and yet still defies attempts at solving it. It is becoming worse with the contemporary economic misfortunes of most countries in the world couple with widespread immorality and disrespect of traditions and norms of behaviour subsumed in negligence of good values.

Ordinarily, stress management, according to Wikipedia encyclopedia, "refers to a wide spectrum of techniques and psychotherapies aimed at controlling a person's levels of stress, especially chronic stress, usually for the purpose of improving every day functioning. However, my take on this is that stress management should be the totality of the efforts, plans, policies, and strategies put in place to prevent, control as well as contain stress [8].

Basically, the problem of stress and stress management, has remained a hard nut to crack because, I believe, is due to poor management strategy. The common stress management techniques do not seem to have much help as the problem continue unabated, hence the need for a more effective strategy. This paper submits that the natural theorists' strategy would be more therapeutic for stress management.

Management of stress involves changing the stressful situation when you can, changing your reaction when you can, taking care of yourself and making time for rest and relaxation [8]. These according to the naturalists could be possible if an individual employs their postulations. The natural theorists like the stoic, Pythagoras, Epicurus and the cynics, adumbrated their different ways of managing stress related problems.

\section{The Stoics}

A stoic is an individual who attempts to live according to stoic doctrine, while stoicism is the philosophy that council's self-control, detachment, and acceptance of one's fate as indentified by the objectives use of reason [9].

The stoics, see the issue of stress from man's relationship with mature. For man must live according to nature or reason. According to Soccio, stoicism emerged as a reaction against the belief that pleasure is always good and pain is always bad or evil. Rather than pursuing pleasure, and avoiding pain, the stoic seeks serenity (peace of minds) through self-discipline. Stoicism asserts that seeking anything but self-control results in avoidable unhappiness. That happiness comes only through detachment from external [10].

Explaining the ethics of the stoics, Omoregbe, says that whether man likes it or not, he has to comply with the laws of nature which regulate everything in the universe. Explaining further, he said that man is not free to comply or not to comply with the laws of nature, for everything in the universe is ruled by these inexorable laws [11]. Basically, the solution to stress and unhappiness, is found in the four cardinal virtues of the stoics namely: prudence, courage temperature, and justice. These virtues are not separable, because if you have one, you have all and if you lack one, then you lack all.

Accordingly, passions, desires, feelings, affection, emotions are opposed to a life of reasoning or living in line with nature, since human desires are insatiable, living by their dictates would bring frustration and unhappiness which eventually brings about stress and depression.

A natural theorist like Seneca who lives around $65 \mathrm{AD}$, gave detachment from material possessions as an antidote to stress, saying that one should be master of his possessions and not slave of his possessions. 
Epictetus who lives between 50-38 AD was another natural theorist who was a stoic. Epictetus posits that man should be able to control his will and apply his knowledge in his conduct. $\mathrm{He}$ contended that self-education consists primarily in cultivating the right attitude of the will, the right disposition of the will for "the essence of good and evil lies in an attitude of the will" [12]. This, in the final analysis would enable the individual to avoid stress and unhappiness.

Marcus Aurelius, a Roman emperor who reigned between 161-180AD, was another natural theorist who practiced stoicism and followed the rules strictly even as a ruler. James Christian [13], while writing on Marcus, explained that this philosopher organized his philosophy around understanding one's inner self and used the knowledge for navigating his life among humans. To achieve this objective, he organized his practice into a set of four virtues of wisdom, justice, fortitude and temperance.

James [13] explained these virtues as follows:

Wisdom : learn what is good and bad, which involvements are beneficial and which are damaging, which concerns are ennobling and which are degrading [13].

Justice : Be honest and fair so that you can always respect yourself; do not be arrogant, thinking you are more than you are; but do not think less of yourself either, thinking you are worth nothing. This particular point of Aurelius may have formed a background to Alfred Adler's psychoanalytic movement called the "Society for Free Psychoanalytic Research". According to Anwana, this theory enables an individual to understand that emphasis must be placed on the importance of the individual and his interaction with environment. The theory also helps the individual reduce his negative evaluation of himself, his feelings and inferiority. Furthermore, it helps an individual to correct his perceptions of events and at the same time, helps him develop a new set of objectives towards which he can direct his behaviour [14]. Basically, and on the strength of the above, stress could be tremendously managed.

Fortitude : develop the strength to withstand courageously "the strings and arrows of outrageous fortunes".

Temperance : develop control of one's passions, resist excesses and learn to strike a balance in all life [14]. From the above one can understand that one's life could be free of stress and pains, when an individual develops and practice these virtues, then such can manage himself out of stress.

On the whole, the stoics admonish man not to depend on materials possessions because such cause disturbances and reduce internal peace and tranquility. To reduce stress and unhappiness, then, we must learn to be unattached and independent on material possession.

Epicurus (-270 BC) was born in Asia Minor city of Samos. Epicurus formed a school called "the Garden" where Epicureanism was practiced. This was a place free from the social, political and even philosophical turmoil of Athens. For the Epicureans, as natural theorists, they opined that an individual can reduce stress and make life pleasant by sober contemplation. They said that people become stressed up when they indulge in sensual pleasure which causes confusion and trouble. Since Epicurus's idea of pleasure is mental tranquility, inner calm, peace of minds, he discourages the accumulation of material possessions. He maintains that stress could be reduced by way of contentment with little possessions. As a natural theorist, he admonishes us not to be afraid because fear cause of mind always and be courageous.

\section{Pythagoras}

He was an Ionian who formed as philosophic - religious community associated with Orphism a kind of religion found in Kroton which explains that man is a mixture of both device and human elements. For the Pythagoreans, stress is best controlled through religion and music [15]. For Pythagoras, one can be peaceful and stress free if he or she is religious in life by way of purification and an ascetic way of life style [15]. On the other hand, stress is reduce if one who is stressed listeners to music. The efficacy of this therapy can be seen in the fact that music is used for relaxation and can ease tension and relax the muscles.

Music according to these natural theorists is a useful tool for stress reduction and could be mysterious in solving stress related conditions. For instance, when King soul was pertubed by problems, he often listened to music played by David with his little instrument (1 Samuel 16, verse 
14). From the above, we can see that. Music plays an important role in stress management, this may be why it is commonly said that music is food for the soul.

\section{Conclusion}

So far we have been discussing stress and stress management from the perspectives of the natural theorists. We have seen that these natural theorists/philosophers provided the natural measures for stress management and these measures in turn formed the foundation for modern ways of managing stress related problems. For instance, if one avoids, luxurious living, one can prevent diseases such as diabetes, obesity, heart attack, strokes etc.

Again, one can avoid pain and mental stress, if one avoids material possessions which come with negative consequences. It is believed that religion is the opium of the society according to Karl max, and surely, one who embraces religion seriously and honestly too, can achieve a stress free life which others can emulate [11]. We can also say that music is a natural therapy that soathes the soul. This may be why it is common in Africa particularly, to sing or play native songs for a child that is disturbed emotionally, or put differently, that, when a child cries because of fear or stress, one can sing a lullaby for the baby. All these measures and other ones offered by the naturalists could go a long way in stress management, and stress elimination.

\section{References}

[1] N. Stasiulis, "The mind of the political and social animal," Filosofija, Sociologija, vol. 30, no. 3, pp. 163-165, 2019. doi: 10.6001/fil-soc.v30i3.4037.

[2] OAD. Definition of stree. Oxford University Press. [Online]. Available: https://www.oxfordlearners dictionaries.com/definition/english/goal [Accessed: Marc 1, 2020].

[3] P. Heidenreich, and I. Pruter, Handbook of stress: Causes, effects and control. In Handbook of Stress: Causes, Effects and Control, 2009.

[4] A. Tsutsumi, K. Kayaba, et al, "Prospective study on occupational stress and risk of stroke," Archives of Internal Medicine, vol. 169, no. 1, pp. 56-61. 2009. doi: 10.1001/archinternmed.2008.503.

[5] J. A. Tur, A. Sureda and A. Pons, "Evaluation of Oxidative Stress in Humans," In Obesity, pp. 191-196, 2018. doi: 10.1016/b978-0-12-812504-5.00009-x.

[6] O. E. Okon, Introductory Animal Physiology. Calabar: Nature Printers, 2017.

[7] P. A. Potter, and A. G. Perry, "Fundamental of Nursing Eight Edition," In Elsevier. [Online]. Available: https://doi.org/10.1109/ISCA.2016.31 [Accessed: February 2, 2020].

[8] A. S. Hornby, Oxford Advanced Learners' Dictionary. Oxford: Oxford University Press, 2001.

[9] C. A. Simon, and D. C. Nice, "Stoicism: Relevant Applications for Contemporary Public Administration," American Review of Public Administration, vol. 27, no. 2, pp. 168-180, 1997. doi: $10.1177 / 027507409702700204$

[10] D. Soccio, Archtypes of wisdom: An Introduction to Philosophy. Belmont: Wadsworth, 2007.

[11] D.Weidner, "Prophetic Criticism and the Rhetoric of Temporality: Paul Tillich's Kairos Texts and Weimar Intellectual Politics," Political Theology, vol. 21, no. 1, pp. 71-88, 2020. doi: 10.1080/1462317X.2020.1730558.

[12] J. Omoregbe, "Knowing Philosophy," Lagos Joja Educational Research and Publishers Limited, 1990.

[13] L. James, Christian Philosophy: An Introduction to the Art of Wondering. Belmont: Wadsworth, 2003.

[14] U. E. Anwana, Theories of Councilling and Psychotherapy. Calabar: University of Calabar Press, 2005.

[15] G. P. Chrousos, "Albert Struyvenberg Medal Lecture Systems Biology and the Stress Response: From Pythagoras and the Epicureans to Modern Medicine," European Journal of Clinical Investigation, vol. 42, pp. 1-3, 2012. 